\title{
Study and approbation of ex situ conservation methods for preservation of the biodiversity of wild relatives of culti- vated plants of Kazakhstan
}

\author{
Gulnara Sitpayeva, Tansara Murzatayeva, Saniya Inerbayeva, Karina Makhmudova \\ Institute of Botany and Phytointroduction, Almaty, Kazakhstan
}

Email address:

m.tansara@mail.ru (T. Murzatayeva)

To cite this article:

Gulnara Sitpayeva, Tansara Murzatayeva, Saniya Inerbayeva, Karina Makhmudova. Study and Approbation of Ex Situ Conservation Methods for Preservation of the Biodiversity of Wild Relatives of Cultivated Plants of Kazakhstan. American Journal of Environmental Protection. Special Issue: Applied Ecology: Problems, Innovations. Vol. 4, No. 3-1, 2015, pp. 117-122. doi: 10.11648/j.ajep.s.2015040301.28

\begin{abstract}
Researchers of the laboratory of seed growing and plant protection of RSE "Institute of Botany and Phytointroduction" CS MOS RK are in the process of studying the techniques of the leading seed banks of the world, of their assessment and approbation using seed samples of wild relatives of the cultivated plants of Kazakhstan at their placing for storage. At the Institute of Botany and Phytointroduction of the Ministry of Education and Science of the Republic of Kazakhstan within the scientific-technical program "Botanical variety of wild relatives of cultivated plants of Kazakhstan as a source of enrichment and preservation of the agrobiodiversity gene pool for realization of the Food programme" for 2013-2015 the work on creation of seed bank of wild relatives of cultivated plants (WRCP) of Kazakhstan is being carried out. Since 2013 the employees of the Institute carry out collecting seed material of WRCP. In the present work the results of positive germinating test and planting the seeds of caper grassy (Capparis herbacea Willd.) collected in Kazakhstan are presented.
\end{abstract}

Keywords: Ex situ-Preservation, Germinating Test, Capparis herbacea Willd., Seed Bank, Kazakhstan

\section{Introduction}

In this research work the methods of storing seeds of wild plants in Kazakhstan on the example of the organization and operation of the seed bank of the wild relatives of cultivated plants (WRCP) were studied. Man always engaged in farming and cultivation of plants suitable for food, saved seeds to plant them next year. Modern seed banks pursue the same goal - to keep the genetic diversity of cultivated and wild plants, to ensure the stability of our food supply, ensure the restoration of crops after global catastrophes and provide an important source of material for scientists. Seed samples can be used to develop more productive crops and species that are resistant to pathogens and climate changes [1]. In the world there are more than 1,750 gene banks [2]. Some of them maintain local plants; others act on the global level. Consultative Group on International Agricultural Research, founded in 1971, includes 47 member countries and 11 gene banks, saving 650,000 samples. Genetic diversity is very important for all organisms. If all of them were same, then one pathogen or cataclysm could destroy everything at once. Genetically diverse populations possess more chances to have individuals who can survive and pass on their useful traits to the next generations.

The aim of this work is studying and approving methods of ex situ preservation of seed samples of the wild plants of Kazakhstan.

Research tasks: - to find appropriate conservation methods of seed of the wild plants of Kazakhstan; - to test the available techniques in the conditions of the seed bank of the Institute of Botany and Phytointroduction; - to carry out statistical analysis of linear dimensions and weight of the seeds of Capparis herbacea; - to carry out the germination of seeds of Capparis herbacea Willd.; - to identify ways of further use of the data obtained from the study.

In general, seed banks holding wild species follow the instructions of the International genebank for collecting, processing, storage and use of seeds. But during last 10-20 years the problem and lack of knowledge had formed and it led to more focused researches of ways of seeds of various species. For example, now more eco-geographical understanding of the behavior of seeds during conservation exists 
and more knowledge about the relative longevity of orthodox seeds is available, and that is why we can determine in advance what seeds should be stored using cryo-technology. Research on the development of seeds determined when it was better to collect the seeds which were more resistant to drying and long-term storage; also the best understanding of how the development of seeds can vary between species was formed; it became possible to use them for recovery of species or reintroduction or for evaluating the other ways of their use.

For ex situ conservation of plant diversity in general seed banks hold about 4.6 million accessions, 64 food and forage crops covered by the multilateral system of beneficial use "International Treaty Plant Genetic Resources for Food and Agriculture" [3]. Seed banks create seed germplasm for crop study and other international researches. Seed germinating is the first step in the search of genes to improve quality, productivity and to overcome biotic and abiotic stresses. Seed banking had already been used for ex situ conservation of wild species that were not the relatives of cultivated plants. Until then, it was adopted the Global Strategy for Plant Conservation (GSPC / GSPC) in 2002, thousands of seed samples of wild species were placed into the bank for long-term storage due to the efforts of the Millennium Seed Bank Partnership [4] One of the revised objectives of the GSPC is that at least $75 \%$ of the species of seeds in the world should be included in the ex situ collection, and only $20 \%$ of them are suitable for rehabilitation and restoration program "2020".

Seed banks usually store seed corresponding to the genebank standards $[5,6]$. There are no specific standards for seed storage of wild plant species, and most of the information obtained through the study of crops, with the exception of some species due to the fact that the behavior of the samples is different from the expected. While most of the rules are suitable for similar cultivated and wild species, as well, there are differences between them. Expenses for long-term storage and medium storage varies, for long term storage a large amount of material is required (the temperature must constantly remain low), while the medium-term storage, the base material is distributed over several years.

It is expected that the collection of wild species in seed banks will play an even greater role in the rehabilitation and reconstruction of species in their natural habitats $[7,8]$.

The reason why we have chosen caper grassy as the object of our study is the need to introduce into the culture of the alternative sources of polyunsaturated fatty acids of vegetable origin.

It is well known that people consuming a large number of seafood containing fatty acids from the family $\Omega-3$, less often get sick with metabolic diseases of the civilization, less often suffer from atherosclerosis, coronary heart disease, a cancer of a mammary gland and a thick gut, thrombosis of vessels and asthma [9]. In the conditions of sharply continental climate seafood is not available in large volumes. The alternative sources of polyunsaturated fatty acids are known, it is a series of oil-yielding plants. Attempts to fill up the range of vegetable oils at the expense of cultivars of foreign breeding and their inclusion into the local cultivars of oil-bearing crops, did not give the expected result. In this connection creation of a collection of the domestic wild vegetable species resistant to environmental stresses, which are the alternative sources of the polyunsaturated fatty acids and their further use in breeding programs is urgent.

It is known, that sufficient receipt of polyunsaturated fatty acids (omega-3 and omega-6) is necessary for normal realization of the following processes in a human organism: development and maintenance of the brain function; realization of visual process; the response of the immune system; participation in the synthesis of hormones. The European department of safety of foodstuff (EFSA) has confirmed the fact of improvement of the health state on the background of adequate consumption of the polyunsaturated omega-3 fatty acids with food $[10,11]$. Further, we will be interested in the fatty acids necessary for maintenance of health, not developed by the human organism - unreplaceable or essential fatty acids (EFA). In the EFA composition 5 polyunsaturated fatty acids (PUFA), linoleic, linolenic, arachidonic, eicosapentaenoic and docosahexaenoic, are distinguished. Their amount in the human organism depends on that, how many fats and oils a human person eats. Fatty acids are the basic building blocks not only in the fats contained in tissues of the person, but also taking place in foodstuff. They are the important energy source for any organism [12].

Evans and Barr in 1928 showed the growth delay and fertility decrease of rats whose diet contained no fats but contained vitamins A and D. Further, it was shown that this syndrome of insufficiency can be treated by means of adding into the food linoleic, linolenic and arachidonic acids. Other symptoms of the given syndrome are squamous dermatitis, necrosis and defeat of uric system; the syndrome usually does not result in a lethal outcome. EFA are contained in enough amounts in vegetable oils and in small amount - in animal tissues [13]. People whose diet did not contain EGAs were also affected by squamous dermatitis; in their case infringements of the lipids' transport were noticed. At usual feeding menu adult people had no symptoms of lack of essential fatty acids. Suckling children receiving artificial feeding with the insignificant content of fats were also affected by squamous dermatitis, which was easily treated with the linoleic acid preparation. The disorders connected to the EFA-lack was also observed in patients whose vital activity long time was supported only due to the intravenous feed almost devoid the fatty acids. For prevention of such disorders it is necessary the share of essential fatty acids would be (on caloric content) not less than 1-2 \% from the general requirement for calories [13].

The countries having access to sea riches for producing the food additives containing PUFAs can use sea fish, but in mankind disposal there are also riches of flora. Researches devoted to use of the vegetable material as a source of the PUFA [14-13] are also carried out; in plenty the PUFAs omega- 3 and omega- 6 are contained in linen, soya and nut oils [17-19]. These acids also preset in the other vegetable oils, seeds of sunflower, in the peanut, almonds, avocado and soybeans. 
The researches of the chemical compound and the characteristic of buds, fruit, seeds and oil of capers [20,21] showed that they could be the source of the PUFAs. Absence of toxicity and presence of the expressed antiulcer activity of the capers' fruit oil [22] were confirmed.

Caper grassy or caper spiny (Capparis herbacea Willd. I Capparis spinosa L.) is a perennial shrub that throws its creeping branches whose length is $150 \mathrm{~cm}$. Its leaves are light green and covered with wax, entire, elliptic and petiolate. Capers blossom and fructify since May till August and even October. Flowers are solitary, rare beauty, reveal in the morning and close at noon. Out of the white tinged with pink flower long purple anther stalks stretch out. Fruits are oval-shaped, fleshy and green. They contain a lot of nodular brown seeds [23-25].

They grow on clay and rubbly soils often on solonetzic soils of deserts, the slopes of the lower belts of mountains and their loops, waste grounds and in crop fields.

Growth area of caper grassy: Crimea, Caucasus, Central Asia, Southern Europe, Balkans, Asia Minor, Iran, Afghanistan, Western China.

Distribution of Capparis herbacea Willd. in the territory of Kazakhstan: Prikaspy, Turgaysky region, Northern and Southern Ust-Urt, Betpakdala, Moyun-kum, Pribalkhashye, Turkestan, the Dzhungar, Ile and Kyrgyz Alatau, Karatau, Western Tien Shan.

Economic value: Flower buds are edible and known under the name of "capers". Their fruits ("cucumbers") are also edible. They can be used both in fresh, and in a marinated condition. Oil of seeds is suitable in food. Capparis herbacea is a good melliferous herb. Their nutrition value in 100 grams: proteins $-0.8 \mathrm{~g}$; fats $-0.1 \mathrm{~g}$; carbohydrates $-2.5 \mathrm{~g}$; ashes -0.1 $\mathrm{g}$; water $-85 \mathrm{~g}$. Capers are low-calorie and dietary product containing $14 \mathrm{kcal}$ per $100 \mathrm{~g}$ of fresh product. Calorie of the canned capers is $23 \mathrm{kcal}$ per $100 \mathrm{~g}$ of product. They are recommended to use by everyone including humans suffering from obesity [23-25].

\section{Research area \& Methods}

The work was carried out under the conditions of the seed bank in the laboratory of seed growing and plant protection of the Institute of the Botany and Phytointroduction. For the germination test the seeds of Capparis herbacea Willd. (further Capparis herbacea) collected in the Turkestan region of South Kazakhstan region were selected. In the present work, we used methods applied in seed banks developed by N.I. Vavilov Scientific-research institute of plant growing [8] (Russia, Genebank Standards) and by the ENSCONET [1] (EU): 1) Cleaning and morphological description of seeds; 2) Basic germination test; 3) Documentation maintenance.

The following procedure was used for germination of Capparis herbacea: Seeds germinate very badly; they differ by a stretched (for several years) germination. Before sowing the seeds were incubated for 10 days in the refrigerator at $+2^{\circ} \mathrm{C}$. Then, the seeds first were dipped for 30 seconds into boiling water $\left(100^{\circ} \mathrm{C}\right)$ and then for $20 \mathrm{~min}$ they were being cooled in the cold (about $0^{\circ} \mathrm{C}$ ) water.

Then the seeds were left for 1 day in a wet cotton pouch at room temperature, and then 20 seeds in Petri dishes on wet filter paper at a temperature of $20-25^{\circ} \mathrm{C}$. After the seedlings reached $0.5-0.7 \mathrm{~cm}$ in length, they were put into the soil in pots for germination. At the bottom of the pots claydite was stacked. The composition of the soil for germination: finished soil mix for houseplants and river sand in the ratio 1: 1 . The seedlings of Capparis herbacea were mounted to a depth of 3 $\mathrm{cm}$. After seedling emergence the capers were under the observation every day. At present two plants are noted to have already tillered. By the occurrence of the growing season these plants are planned to be placed either into the larger vegetation pots or to be planted at the experimental plot of the IBP.

Thus we have planned the introduction of Capparis herbacea in conditions of IPB for its further introduction and use in biochemical researches and breeding purposes.

\section{Results \& Discussion}

All seed lots were thoroughly cleaned off all related parts. In some cases, samples were laid in the seed bank in the form in which they were received. In this case, it was documented. Seeds of wild species were cleaned manually using the cleaning devices (sieves and rubber floats). Before each new sample the sieves and graters were cleaned. It is recommended that all cleaning operations must be carried out under the hood to filter dust or to make cleaning in the standard protecting masks. During cleaning, the seeds were checked for damages using an electron microscope and a digital magnifier. Vegetable wastes that were accumulated during the seed cleaning process were destroyed by controlled incineration. Seeds in already treated batches were checked visually and by touch to determine the "empty" seeds.

In each sample the mass of seeds of the WRCP was determined. Depending on the size of the seed there was measured the weight of $10,20,50,100,500$, and 1000 seeds. In each sample the linear dimensions of the seeds (length and width) were determined. After the determination of the mass and linear dimensions of the seeds we began to describe the seed samples intended for banking. To do this, we purified some number of seeds from the pericarp or scales. Then seeds were placed on the object micrometer and photographed with a digital magnifying glass. Thereafter, the color and shape of the seeds were described. Having detected the samples damaged by pests or diseases affected, we gave them to a specialist in plant protection. And then we placed them in quarantine.

The results of the preliminary germination test of seeds of Capparis herbacea can be found in Table 1. Thus, from 523 seeds set on germination there were 128 seeds germinated that was $25.5 \%$ of the total amount. 15 of 128 seedlings sprouted in the pots that were $2.9 \%$ of the total number of seeds set for germination.

Below in Figure 1 the photo of seedlings of Capparis herbacea is presented. 


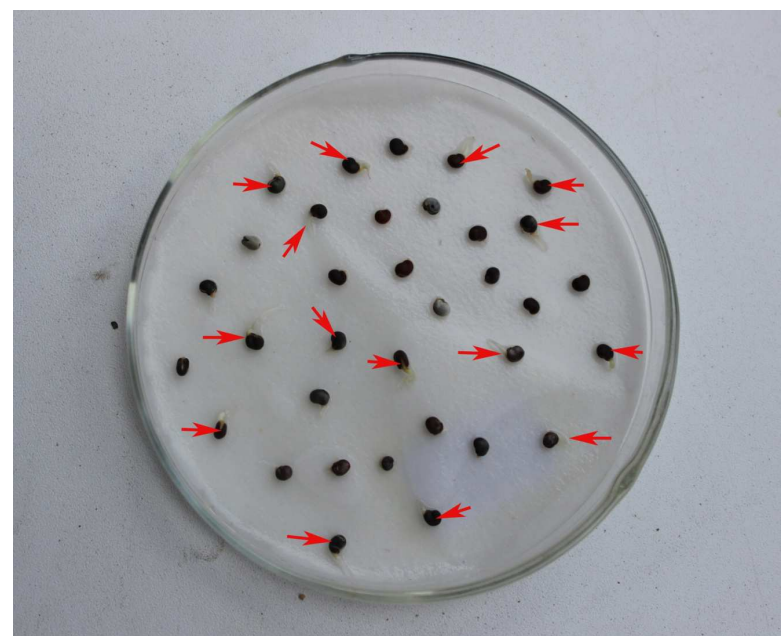

Figure 1. Seeds of Capparis herbacea: Germination Test, Seedlings, 28.08.14

In Figure 2 you can see the first plantlet of Capparis herbacea in the vegetation pot.

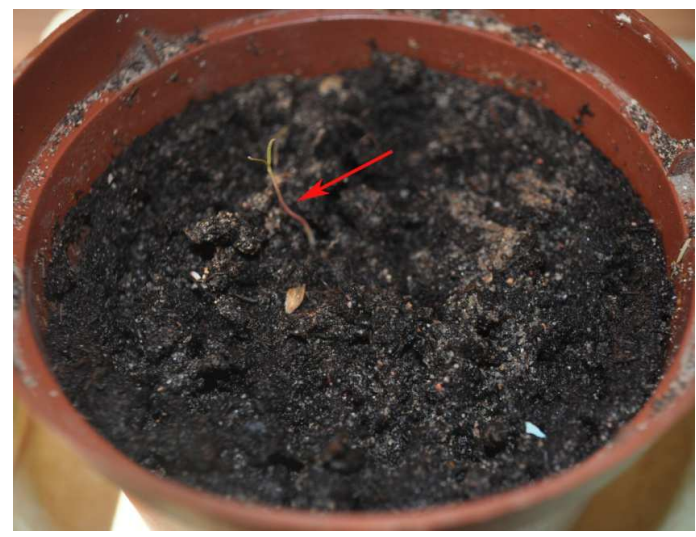

Figure 2. First plantlet of Capparis herbacea in the vegetation pot, 09.09.14

In figure 3 you can see adult plants of Capparis herbacea in the vegetation pots.

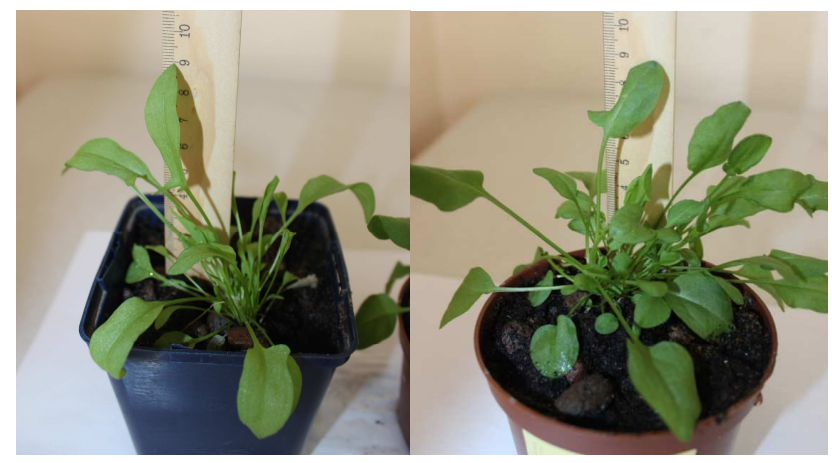

Figure 3. Capparis herbacea plants in the vegetation pot, 23.02 .15
In Table 2 the description of the seed samples of Capparis herbacea is presented.

\section{Conclusion}

Researches and obtained data led to the following conclusions:

1. Study of literature let us concluded:

- Creation of seed banks of wild plants is national importance for a separate state and international significance as a whole, as it allows us to preserve the genetic diversity of flora;

- Scientists around the world, being in close cooperation with each other, developed requirements for genetic banks of cultivated plants, these requirements have further formed the basis of seed banks of wild species of plants;

- For the successful placing a sample into the seed bank it must first be cleaned, dried (15\%) tested for moisture content, and tightly packed;

- Samples laid down for storage into the seed bank were divided into two collections: active (short-term storage) and a basic (long term storage). But in both cases it is better to select a long-term storage conditions $\left(-20^{\circ} \mathrm{C}\right)$;

- In a month after storage under long-term storage conditions the seed samples must be subjected to the basic germinating test (2 replications of 100 seeds);

- It is always keeping documented records that are entered into the database. The exchange of data between the seed banks is compulsory;

- Each 5-10 years the seed samples of the basic collection being in long-term storage should be subjected to regeneration test;

- The samples may be sent to the applicant (seed banks or other interested parties).

2. As a result of working with samples of the seed bank of the RSE "IBP" the seed samples of Capparis herbacea were described (linear dimensions of the seeds, shape, color, weight of 1000 seeds, the presence/absence of pests and diseases).

3. In the laboratory conditions the positive germination test of seeds of Capparis herbacea was carried out.

4. In the laboratory conditions the first plantlets of Capparis herbacea were grown in the vegetation pots.

5. To start the introduction of Capparis herbacea its planting out at the experimentation plot of the IBP was planned.

Table 1. Number of seeds of Capparis herbacea Willd.: Germination Test

\begin{tabular}{lllll}
\hline \multirow{2}{*}{ Name of the sample } & Total number of seeds & $\begin{array}{l}\text { Number of the Germinated } \\
\text { (pieces) }\end{array}$ & \begin{tabular}{l} 
Number of the Sprouted Plants in the Pots (pieces) \\
\cline { 3 - 5 }
\end{tabular} & Seeds (pieces) \\
with the Cotyledonous & $\begin{array}{l}\text { with the } \\
\text { Leaves }\end{array}$ & Leaves \\
\hline Capparis herbacea Willd. & 523 & 128 & 4 & 11 \\
\hline
\end{tabular}


Table 2. Description of Seed Samples of Capparis herbacea Willd., Collected in 2013

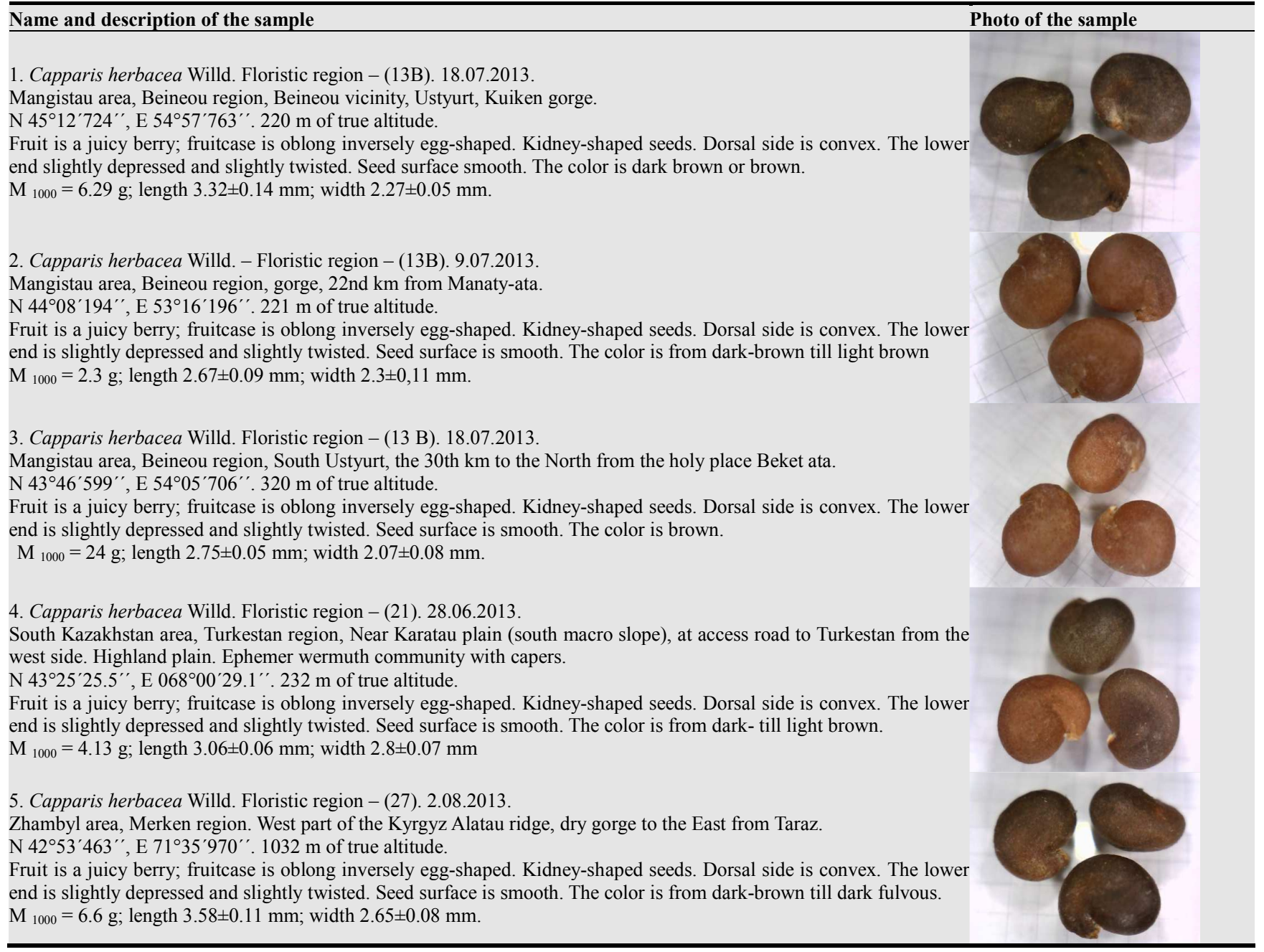

\section{Acknowledgements}

This work was made possible due to the state funding of the Republic of Kazakhstan in the frame of the scientific-technical program No. 0199 "Botanical variety of wild relatives of cultivated plants of Kazakhstan as a source of enrichment and preservation of the agrobiodiversity gene pool for realization of the Food programme", 2013-2015.

\section{References}

[1] ENSCONET (2009). ENSCONET. Curation Protocols \& Recommendations. www.ensconet.eu/download

[2] Fiona R.H., Probert R.J. (2013). Advances in seed conservation of wild plant species: a review of recent research. Conservation physiology. Vol. 1. pp. 1-11. http://conphys.oxfordjournals.org

[3] ISTA (2013). International Rules for Seed Testing. International Seed Testing Association, Bassersdor.

[4] Millennium Seed Bank Project website www.kew.org/msbp

[5] FAO/IPGRI (1994). Genebank Standards. Food and Agriculture Organization of the United Nations, International Plant Genetic Resources Institute, Rome.
[6] FAO (2013). Draft genebank standards for plant genetic resources for food and agriculture. http://www.fao.org/agriculture/crops/core-themes/theme/seeds -pgr/conservation/gbs/en/ (accessed April 2013).

[7] Merritt DJ, Dixon KW (2011). Restoration seed banks - a matter of scale. Science 332: pp. 424-425.

[8] Plilipenko G.I. Methods of the ex situ conservation of the genetic plant resources (2013). Presentation http://www.myshared.ru/slide/392931/

[9] http://www.norwesol.ru/most-important-omega-3\#dpa

[10] http://www.nutri-facts.org/rus/nezamenimye-zhirnye-kisloty/e ssential-fatty-acids/kratkii-obzor

[11] Dolecek TA, Granditis G. Dietary polyunsaturated fatty acids and mortality in the Multiple Risk Factor Intervention Trial (MRFIT) // World Rev Nutr Diet. 1991. Vol.66. pp. 205-216.

[12] http://club.uliabell.e-gloryon.com/0907721872

[13] http://humbio.ru/humbio/biochem/001a55c7.htm

[14] Kamysheva I.M. Development of technologies of complex processing the amaranth seed for food goals: Thesis of the candidate of sciences (Technique). Saint-Petersburg: All-Russia scientific-research institute of fats, 2000. - $20 \mathrm{pp}$. (published in Russian) 
122 Gulnara Sitpayeva et al: : Study and Approbation of Ex Situ Conservation Methods for Preservation of the Biodiversity of Wild Relatives of Cultivated Plants of Kazakhstan

[15] Tsekhanovskiy S.N., Morozova Z.F., and Sergiyevskaya I.V. Application in clinical practice the "Vegetable oil "Forma" (made of amaranth seeds) // New and unconventional plants and perspectives of their use: $5^{\text {th }}$ International symposium. - M., 2003. Vol 1. pp. 98-100. (published in Russian).

[16] http://life-spb.ru/others/amaranth-oil-clinical-research.htm

[17] Tyutyunnikov B.N. Chemistry of lipids - M.: Kolos, 1992. 448 pp. (published in Russian)

[18] Bezzubov L.P. Chemistry of lipids. M.: Food industry. 1975. 280 pp. (published in Russian)

[19] Scherbakov V.G. Chemistry and biochemistry of treatment the oil seeds - M.: Food industry. 1977. 180 pp. (published in Russian).
[20] http://www.minclinic.ru/drugs/lekarstvennie svoystva pishevi h_rasteniy/kapersy.html

[21] Akgül A.and Ôzcan M. Some compositional characteristics of capers (Capparis spp.) seed and oil // GrasasyAceites. - 1999. - Vol.50., Fase.1. - pp. 49-52.

[22] Rakhimov I.F. Biochemical and pharmacological features of sea-buckthorn and caper oils in Tajikistan. Dissertation of doctor of sciences (Medicine): 14.00.25. Dushanbe: Chemistry, 2006. 254 pp. (published in Russian)

[23] http://innature.kz/articles.php?article_id=1651

[24] http://edaplus.info/produce/caper.html

[25] http://www.plantarium.ru/page/view/item/8076.html 